\title{
PREVALENCE AND DETERMINANTS OF BEHAVIORAL PROBLEMS AMONG ADOLESCENTS LIVING IN ORPHANAGE FACILITIES OF DISTRICT PESHAWAR, KHYBER PAKHTUNKHWA, PAKISTAN
}

\section{Faiza Khurshid $^{\varpi}$, Naheed Mahsood ${ }^{2}$, Zeeshan Kibria ${ }^{3}$}

\begin{abstract}
OBJECTIVE: To determine the prevalence and determinants of behavioral problems among adolescents living in orphanage facilities of District Peshawar, Pakistan.

METHODS: This cross-sectional survey was conducted from February to July 2016 in the orphanages of District Peshawar, Pakistan registered with Social Welfare Department. Total of 360 adolescents of both genders of age group 10 to 19 years were included in the study. Data was collected using Strength and Difficulty Questionnaire (SDQ). Data was analyzed using SPSS VI 6.
\end{abstract}

RESULTS: Out of 360 adolescents 334 (92.8\%) were males and 26 (7.2\%) females. The prevalence of behavioral problem was $33.9 \%$. Among the behavioral problems, conduct problem had the highest prevalence of $24.4 \%$ followed by emotional problem (18.6\%), peer problem (18.1\%), hyperactivity $(8.3 \%)$ and pro-social behavior $(2.8 \%)$. The results of cross comparative analysis showed that age, gender, type of orphanage and parent's status were significantly associated with behavioral problems $(p<0.05)$. However, time period of institutionalization and age at parents' demise had insignificant $(p>0.05)$ association with behavioral problems.

CONCLUSION: A high burden of behavioral problems was found among adolescents living in orphanages of District Peshawar. The determinants of behavioral problems found in this study, may be taken as target of intervention to reduce behavioral problems among adolescents living in orphanages.

KEY WORDS: Adolescents (MeSH), Adolescent Behavior (MeSH), Behavior $(\mathrm{MeSH})$, Problem Behavior $(\mathrm{MeSH})$, Strength and Difficulty Questionnaire (Non-MeSH).

THIS ARTICLE MAY BE CITED AS: Khurshid F, Mahsood N, Kibria Z. Prevalence and determinants of behavioural problems among adolescents living in orphanage facilities of district Peshawar, Khyber Pakhtunkhwa, Pakistan. Khyber Med Univ J 2018; 10(2):95-100.

\section{INTRODUCTION}

Candide hildhood is the most important and decisive period of human life and a healthy childhood is crucial for future growth and development.' Alongside developmental changes, the periods of childhood and adolescent are under the influence of social, emotional, physical and biological factors which also make it nerve-racking, and thus, making the children more susceptible to developing behavioral, psychological, and emotional problems. ${ }^{2,3}$ Millions of orphans and abandoned children across the world are deprived of this crucial phase of life. In the absence of the child's parents, grandparents or reluctant relatives not willing to take care of the child, orphanage act as an institution to provide care and support for these unfortunate children. ${ }^{4}$

The orphanages can provide a protected and positive substitute to offensive and unsecure family or community environments but they can't give individualized and family fostering.
$1^{凶}$ Institute of Public Health and Social Sciences, Khyber Medical University, Peshawar, Pakistan

Email: faizakhurshid62@gmail.com

2 Assistant Professor, Department of Medical Education, Khyber Girls Medical College Peshawar, Pakistan

3 Deputy Director, Office of Research Innovation \& Commercialization (ORIC), Khyber Medical University, Peshawar, Pakistan

Date Submitted: April 12, 2017

Date Revised: June 18,2018

Date Accepted: June 20, 2018

Orphanage children are exclusively susceptible to many psychosocial threats of institutional care compared to children living with their families. ${ }^{6}$ Despite having a proper shelter, children in institutional care found difficulties regarding reading, language, attention, poor physical health, poverty, attachment disorder, mental health difficulty and inadequate social skills. ${ }^{6,7}$ Some circumstances could increase the risk for behavioral and developmental problems, for example, abuse, neglect, and malnutrition can cause effects for long-lasting. ${ }^{8}$

Behavioral problem is defined as emotional problem, conduct problem, hyperactivity, peer problem and lack of pro-social behavior.' An emotional problem affects a person's ability to be happy and control their emotions. Conduct problem is a dreary and determined example of conduct in adolescents characterized by serious rule violations, aggressive behavior, disobedience and dishonesty or theft. Hyperactivity is a state of excess activity that is manifested by symptoms such as excessive movement, fidgeting, jumpiness or nervousness. Peer problem involves issues in getting along with peer and experiencing negative feelings or dislikeness towards peer. Pro social behavior is a social conduct that advantages other individuals or society in general, for example, co-working, sharing, helping, giving and volunteering.'

Institutionalized children are low in confidence, exhibit negative behavior, lack sympathy, exhibit discriminate affection towards adults and susceptible to disobedience. ${ }^{10}$ These children have a disproportionately high prevalence of behavioral problems and mental health 
TABLE I: FREQUENCIES AND PERCENTAGES OF STUDY VARIABLES

\begin{tabular}{|l|l|c|c|}
\hline & \multicolumn{1}{|c|}{ Variables } & $\begin{array}{c}\text { Frequency } \\
(\mathbf{n = 3 6 0 )}\end{array}$ & Percentage \\
\hline \multirow{4}{*}{ No of } & Dar ul Atfal & 25 & 6.9 \\
Adolescents in & Social Welfare Home & 15 & 4.2 \\
Orphanages & Aghosh Alkhidmat & 81 & 22.5 \\
& Almadina International & 40 & 11.1 \\
& School and Hostel & 199 & 55.3 \\
\hline \multirow{3}{*}{ Gender } & Mercy Educational Complex & 334 & 92.8 \\
& Male & 26 & 7.2 \\
\hline \multirow{3}{*}{ Behavioral } & Female & 67 & 18.6 \\
Problems & Emotional Problem & 124 & 34.4 \\
& Conduct Problem & 30 & 8.3 \\
& Hyperactivity & 65 & 18.1 \\
& Peer Problem & 10 & 2.8 \\
& Pro-social behaviour & 122 & 33.9 \\
\hline
\end{tabular}

irregularities like anxiety, aggression and more depression as compared to family raised children,. ${ }^{11,12}$ These factors were causes of receiving institutional care, moves two or more times between institutions, age at first admission, death of one or both of the parents, malnutrition, higher length of stay in the facility, foster mother depression and low level of education of foster mother., ${ }^{5,13}$ On the other hand, regular contact of the orphans with orphanage staff, classroom teachers, parents or relatives, perceived social support, appropriate task involvement and competency were protective against behavioral problem. ${ }^{14}$

The lives of millions of people around the world are affected by behavioral problems, but it is studied less than anxiety disorders, psychotic disorders, mood disorders and is also rated lower than drug or alcohol addiction. ${ }^{15}$ Variable prevalence of behavior problems has been reported from Brazil $(23.5 \%)^{16}$, Egypt $(34.70 \%)^{17}$, Sri Lanka $(19.2 \% \text { and } 13.8 \%)^{18.19}$ Bangladesh $(15 \%)^{20}$ and India $(12.6 \%)^{21}$ in various settings. The prevalence was significantly higher among the boys, ${ }^{18,19}$ while no significant differences among urban slums, urban middle class and rural areas. $^{21}$

In Pakistan, a study on emotional and behavioral problems among students of $4^{\text {th }}$ and $5^{\text {th }}$ classes, aged 9-1I years, attending three different schools (one public and two ordinary) reported $9.3 \%$ prevalence of behavioral problems. ${ }^{22}$ Similarly another study conducted in 5-11-years-old children attending main stream private and community schools in Karachi reported that $34 \%$ of children were found having behavioral problems. ${ }^{23}$ Another study conducted in working children aged II of behavioral problems. ${ }^{24}$

Orphans are the special group of children who are generally behavioral problems even when raised in well run institutions. According to literature search, limited research has been conducted in Pakistan on behavioral problems among the adolescents in orphanages. Insufficient baseline data is available which cannot make a solid ground for the strengthening of indigenous orphanages and foster institutions. This study was planned to determine the prevalence and determinants of behavioral problems among adolescents living in orphanage facilities of District Peshawar, Pakistan. This survey would provide baseline data about the existence of behavioral problems among the adolescents in orphanages and provide some guidelines to health authorities and social welfare department to take necessary steps regarding this issue to protect this vulnerable population from behavioral problems.

\section{METHODS}

This cross-sectional survey was conducted from February to July 2016 16 years old reported $9.8 \%$ prevalence underprivileged and susceptible to in the orphanages of District Peshawar, KPK, Pakistan. There were total five orphanages in district Peshawar, Pakistan registered with Social Welfare Department i.e. Dar-ul-Atfal, Social Welfare Home, Aghosh Alkhidmat, Almadina International School and Hostel and Mercy Educational Complex. The first two were run by the Government and other three were run by private sector.

There were approximately 930 children in the five orphanage facilities. The number of Adolescents in the age group 10 to 19 was approximately 360 . All adolescents of both genders of age group 10 to 19 years were included in the study and the adolescents who were not willing to participate in the study or already been diagnosed with psychological and behavioral problems by physician before entering the orphanage were excluded.

The approval/permission for the study was obtained from Khyber medical University (KMU) Ethics board. The purpose of the study was explained to the head of the orphanages and an informed written consent was obtained from them. Similarly, a written consent was also taken from the wardens of the adolescents and from adolescents who were above or 15 years of age.

The data was collected in the orphanages through a validated and selfadministered version of Strength and Difficulty Questionnaire (SDQ). The questionnaire was originally in English language which was translated into Urdu language and then re-translated into English language to validate the meaning of the questions. It measures 25 attributes; some positive and some negative. The items are grouped into five sub-scales of five items each, generating scores for Emotional problem, Conduct problem, Hyperactivity, Peer problem and Prosocial behavior. ${ }^{25}$ Before data collection, an appropriate level of trust was developed with the adolescents. Each question was explained to them and then they were asked to mark the correct option.

For data analysis, SPSS version 16 was used. Mean and SD were calculated for Age. Frequencies and percentages were 
Table II: ASSOCIATION OF BEHAVIORAL PROBLEMS WITH INDEPENDENT VARIABLES

\begin{tabular}{|c|c|c|c|c|c|c|c|}
\hline \multirow[b]{2}{*}{ Determinants } & \multicolumn{7}{|c|}{ Behavioral Problems } \\
\hline & $\begin{array}{l}\text { Emotional } \\
\text { Problem }\end{array}$ & $\begin{array}{l}\text { Conduct } \\
\text { Problem }\end{array}$ & Hyperactivity & $\begin{array}{c}\text { Peer } \\
\text { Problem }\end{array}$ & $\begin{array}{l}\text { Prosocial } \\
\text { Behavior }\end{array}$ & $\begin{array}{c}\text { Total } \\
\text { Difficulty } \\
\text { Score }\end{array}$ & $\begin{array}{c}P \\
\text { Value }\end{array}$ \\
\hline \multicolumn{7}{|c|}{ Age Group (years) } & \multirow{7}{*}{$<0.01$} \\
\hline \multirow{2}{*}{$\begin{array}{c}\text { Group I } \\
(10-12.9)\end{array}$} & 30 & 87 & 25 & 42 & 3 & 87 & \\
\hline & $15.80 \%$ & $45.80 \%$ & $13.20 \%$ & $22.10 \%$ & $1.60 \%$ & $45.80 \%$ & \\
\hline \multirow{2}{*}{$\begin{array}{c}\text { Group } 2 \\
(13-15.9)\end{array}$} & 31 & 32 & 5 & 15 & 5 & 29 & \\
\hline & $25.40 \%$ & $26.20 \%$ & $4.10 \%$ & $12.30 \%$ & $4.10 \%$ & $23.80 \%$ & \\
\hline \multirow{2}{*}{$\begin{array}{c}\text { Group } 3 \\
(16-18.9)\end{array}$} & 6 & 5 & 0 & 8 & 2 & 6 & \\
\hline & $12.50 \%$ & $10.40 \%$ & $0.00 \%$ & $16.70 \%$ & $4.20 \%$ & $12.50 \%$ & \\
\hline \multicolumn{7}{|l|}{ Gender } & \multirow{5}{*}{$<0.01$} \\
\hline \multirow{2}{*}{ Male } & 66 & 102 & 29 & 60 & 10 & 107 & \\
\hline & $19.80 \%$ & $30.50 \%$ & $8.70 \%$ & $18.00 \%$ & $3.00 \%$ & $32.00 \%$ & \\
\hline \multirow{2}{*}{ Female } & 1 & 22 & 1 & 5 & 0 & 15 & \\
\hline & $3.80 \%$ & $84.60 \%$ & $3.80 \%$ & $19.20 \%$ & $0.00 \%$ & $57.70 \%$ & \\
\hline \multicolumn{7}{|c|}{ Type of Orphanage } & \multirow{5}{*}{$<0.01$} \\
\hline \multirow{2}{*}{ Government } & 3 & 36 & 6 & 17 & 0 & 37 & \\
\hline & $7.50 \%$ & $90.00 \%$ & $15.00 \%$ & $42.50 \%$ & $0.00 \%$ & $92.50 \%$ & \\
\hline \multirow{2}{*}{ Private } & 64 & 88 & 24 & 48 & 10 & 85 & \\
\hline & $20.00 \%$ & $27.50 \%$ & $7.50 \%$ & $15.00 \%$ & $3.10 \%$ & $26.60 \%$ & \\
\hline
\end{tabular}

calculated for gender and behavioral problems. Chi-square test was used to determine the association of the Age, gender, type of orphanage, time period of institutionalization, parent's status and age at parent's demise with these behavioral problems.

\section{RESULTS}

A total of 360 adolescents from five orphanages registered with Social Welfare Department were included in the study, out of them $334(92.8 \%)$ were males and $26(7.2 \%)$ females. The prevalence of behavioral problem was $33.9 \%$. Among the behavioral problems, Conduct problem had the highest prevalence $24.4 \%$ as shown in the following Table I.

The determinants of behavioral problems age, gender, and type of orphanage all were significantly associated with behavioral problems as shown in Table II.

Similarly, the time period of institutionalization and age at parents' demise were statistically not significant. However, there was significant association between parent's status and behavioral problems as shown below in Table III.

\section{DISCUSSION}

This study has provided baseline data regarding the behavioral problems among adolescents living in orphanage facilities of District Peshawar, Khyber Pakhtunkhwa, Pakistan. This study revealed an overall prevalence of $33.9 \%$ of behavioral problems. Among the behavioral problems, conduct problem had the highest prevalence of $24.4 \%$ followed by emotional problem $18.6 \%$, peer problem $18.1 \%$, hyperactivity $8.3 \%$ and pro-social behavior $2.8 \%$.

The results of this study are comparable to a study from Karachi, Pakistan, conducted to determine the behavioral problems among children living in either in an SOS Village or conventional orphanages that reported $33 \%$ and $39 \%$ prevalence of behavioral problems based on the ratings of foster mothers, and teachers, respectively. ${ }^{26}$ Similarly, a prevalence of $26.9 \%$ was reported from a similar study conducted in Bangladesh to determine the prevalence of behavioral and emotional disorders among the orphans and factors associated with these disorders. ${ }^{13}$ Many studies have been conducted on general children and adolescents. A study conducted in Egypt revealed that
$20.60 \%$ children were in abnormal category with more frequently reported conduct and peer related problems as found by the parents' ratings. ${ }^{17}$ In the district of Gampaha, Sri Lanka, the prevalence of externalizing behavior problems in 4 to 6 years old children was estimated as $19.2 \%{ }^{18}$, and another study conducted in the Kandy district indicated a $13.8 \%$ prevalence of emotional and behavioral problems. ${ }^{19} \mathrm{~A}$ $15 \%$ prevalence of behavioral problem was found in 5 to 10 years old children in a similar study conducted in Bangladesh ${ }^{20}$, and another study reported $12.6 \%$ prevalence of behavioral problem in India. ${ }^{21}$ Whereas in Karachi, Pakistan, $9.3 \%$ and $34 \%$ prevalence were found in school children, ${ }^{22,23}$ and that of $9.8 \%$ in working children. ${ }^{24}$

These findings revealed that the prevalence of behavioral problems was higher in children and adolescents living in orphanages than general children and adolescents. The prevalence of behavioral problem found in this study was matching to that found in Karachi. ${ }^{26}$

Among the determinants of behavioral problems age had significant association with the total behavioral problems. The age group 10 to 12.9 had the highest 
Table III: ASSOCIATION OF BEHAVIORAL PROBLEMS WITH INDEPENDENT VARIABLES

\begin{tabular}{|c|c|c|c|c|c|c|c|}
\hline \multirow[b]{2}{*}{ Determinants } & \multicolumn{7}{|c|}{ Behavioral Problems } \\
\hline & Emotional Problem & $\begin{array}{l}\text { Conduct } \\
\text { Problem }\end{array}$ & Hyperactivity & $\begin{array}{c}\text { Peer } \\
\text { Problem }\end{array}$ & $\begin{array}{l}\text { Prosocial } \\
\text { Behavior }\end{array}$ & $\begin{array}{c}\text { Total } \\
\text { Difficulty } \\
\text { Score }\end{array}$ & $\mathbf{P}$ Value \\
\hline \multicolumn{7}{|c|}{ Time Period of Institutionalization (years) } & \multirow{7}{*}{0.81} \\
\hline \multirow{2}{*}{$\begin{array}{c}\text { Group I } \\
(1-4.9)\end{array}$} & 40 & 70 & 17 & 36 & 6 & 76 & \\
\hline & $20.40 \%$ & $35.70 \%$ & $8.70 \%$ & $18.40 \%$ & $3.10 \%$ & $38.80 \%$ & \\
\hline \multirow{2}{*}{$\begin{array}{c}\text { Group 2 } \\
(5-8.9) \\
\end{array}$} & 21 & 46 & 13 & 21 & 3 & 40 & \\
\hline & $15.60 \%$ & $34.10 \%$ & $9.60 \%$ & $15.60 \%$ & $2.20 \%$ & $29.60 \%$ & \\
\hline \multirow{2}{*}{$\begin{array}{l}\text { Group } 3 \\
(9-12.9) \\
\end{array}$} & 6 & $8.00 \%$ & 0 & 8 & 1 & 6 & \\
\hline & $20.70 \%$ & $27.60 \%$ & $0.00 \%$ & $27.60 \%$ & $3.40 \%$ & $20.70 \%$ & \\
\hline \multicolumn{7}{|c|}{ Age at Parents Demise (years) } & \multirow{7}{*}{0.91} \\
\hline \multirow{2}{*}{$\begin{array}{l}\text { Group } \\
(1-4.9) \\
\end{array}$} & 33 & 65 & 14 & 30 & 4 & 61 & \\
\hline & $18.60 \%$ & $36.70 \%$ & $7.90 \%$ & $16.9 \&$ & $2.30 \%$ & $34.50 \%$ & \\
\hline \multirow{2}{*}{$\begin{array}{l}\text { Group 2 } \\
(5-10.9) \\
\end{array}$} & 28 & 54 & 14 & 35 & 6 & 56 & \\
\hline & $17.20 \%$ & $33.10 \%$ & $8.60 \%$ & $21.50 \%$ & $3.70 \%$ & $34.40 \%$ & \\
\hline \multirow{2}{*}{$\begin{array}{c}\text { Group } 3 \\
\text { (II-|4.9) }\end{array}$} & 6 & 5 & 2 & 0 & 0 & 5 & \\
\hline & $30.00 \%$ & $25.00 \%$ & $10.00 \%$ & $0.00 \%$ & $0.00 \%$ & $25.00 \%$ & \\
\hline \multicolumn{7}{|l|}{ Parents Status } & \multirow{5}{*}{$<0.01$} \\
\hline \multirow{2}{*}{$\begin{array}{c}\text { Mother } \\
\text { deceased }\end{array}$} & 26 & 86 & 19 & 46 & 3 & 92 & \\
\hline & $20.60 \%$ & 68.3 & $15.10 \%$ & $36.50 \%$ & $2.40 \%$ & $73.00 \%$ & \\
\hline \multirow{2}{*}{$\begin{array}{c}\text { Father } \\
\text { deceased }\end{array}$} & 41 & 38 & 11 & 19 & 7 & 30 & \\
\hline & $17.10 \%$ & $16.20 \%$ & $4.70 \%$ & $8.10 \%$ & $3.00 \%$ & 12.8 & \\
\hline
\end{tabular}

prevalence $45.8 \%$ of behavioral problems which is similar to the study in which age group 10 to 14 years old had highest percentage of behavioral problems. ${ }^{13}$ The majority of adolescents in orphanages were of age group 10 to I 2.9 years and behavioral problem were also prevalent in this age group, as this is the time period of early adolescence which consists of developmental transition from childhood to adulthood, involving multiple physical, intellectual, personality, and social developmental changes.

A statistically significant association was also found between gender and behavioral problems, the prevalence of behavioral problems was highest in females $57.7 \%$ as compared to males $32.0 \%$ which is in contrast to other studies which reported highest prevalence of behavioral problems among males, except in one study in

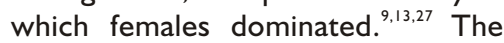
reason for this need to be explored in future studies, yet the possible reason could be that females are more sensitive as compared to males.
Type of orphanage and behavioral problems were significantly associated and it was found that the orphanages run by government had highest prevalence of total behavioral problems $92.5 \%$ than orphanages run by private sectors $26.6 \%$. The facilities provided to the children in private orphanages were better in terms of residence, education, health and extra-curricular activities than those of government orphanages. The private orphanages had invested more funds to provide better quality infrastructure. They had separate spaces for living, dining and extracurricular activities. They also focus more on the children's health by having regular monthly checkups. The children were admitted in high standard private schools to provide good quality education. On the other hand, the government orphanages lack funding and attention. Their infrastructure was inadequate to provide proper space for different requirements of life. They were utilizing common space for children's living and schooling. There was no proper schedule of monitoring health of the children. Similarly, in Karachi the prevalence of abnormal behavior on foster mother-rated overall SDQ was also higher in children in conventional orphanages as compared to that in SOS children. ${ }^{26}$

Time period of institutionalization had insignificant association with behavioral problems. However, this was in contrast to the study in which length of stay had a positive association with the behavioral problems $^{13}$ and another study in which orphanages were found to be protective against behavioral problems. ${ }^{26}$

No significant association was found between Age at parent's demise and total behavioral problem. The results contradicts with another study conducted in orphanages in Dhaka city where the prevalence of psychiatric disorder was highest among the children whose parents died at or before 4 years of age than those whose parents died after completion of four years. ${ }^{20}$ In another study conducted in Bangladesh, behavioral problems were found more among the children who 
had not stayed with parents before coming to orphanage. ${ }^{13}$

The association of parent's status with behavioral problem was significant. Behavioral problems were highest among those adolescents whose mothers were deceased $(73.0 \%)$ than whose fathers were deceased (I2.8\%). Similar results were obtained by Anna Freud who concluded from several case studies that children living in orphanages are doomed to fail psychologically because of maternal deprivation ${ }^{28}$ and another psychiatrist John Bowlby also reported that maternal deprivation was the central issue causing psychological damage to orphanage children. ${ }^{29}$

Due to limited time, cross sectional study design was selected, which has a limitation that it cannot find casual associations.

\section{Conclusion:}

A high burden of behavioral problems was found among adolescents living in orphanages of District Peshawar, Pakistan. The determinants of behavioral problems found in this study, may be used as the target of intervention to reduce behavioral problems among adolescents living in orphanages.

\section{ACKNOWLEDGMENT}

We are grateful to Khurram Sheraz \& Aliya Durrani for their kind help during preparation, proof reading and submission of the manuscript.

\section{REFERENCES}

I. Regional training seminar on Guidance and Counseling Module 4. Behavior modification. UNESCO. February 2000:1-69. [Cited on: April 02, 2017]. Available from URL: http://unesdoc.unesco.org/images/ 00 I 3/00 I 304/I30426e.pdf

2. Nicolson D, Ayers H. Adolescent problems: A practical guide for parents and teachers. London: David Fulton Publishers Ltd; 1997.

3. Caspi A, Taylor A, Moffitt T, Plomin R. Neighborhood Deprivation Affects Children's Mental Health: Environmental Risks Identified in a Genetic Design. Psychol Sci
2000; I (4):338-42. DOI: I0. IIII/ | 467-9280.00267

4. Worldwide Children Statistics. [Cited on: April 02, 2017]. Available from URL: http://www.sos-usa. org/ our-impact/childrens-statistics

5. Koumi EL, Mohamed A, Ali YF, El Banna EA, Youssef UM, Raya YM, et al. Psychiatric morbidity among a sample of orphanage children in Cairo. Int J Pediatr 20 I 2;20 I 2: I-7.

6. Gertler P, Martinez S, Levine D, Bertozzi S. Losing the presence and presents of parent: How parental death affects children. Dev Psychol 2003;25:525-31.

7. Global Facts about Orphanages 2009. [Cited on: April 02, 2017]. Available from URL: http://www. handstohearts.org/wp-content/ uploads/201 I/04/Global-FactSheet-on-Orphanages_BetterCare Network.pdf [Cited On: February 2, 2016]

8. Valley health.com. The Impact of Early Orphanage Live on Development Valley Health System. [Cited on: April 02, 2017]. Available from URL: http://www.valleyhealth.com/ adoptionaspx?ld $=\mid 78$

9. Hussein SA. Dual Informant Ratings of Emotional and Behavioral problems among Primary School Children. Pak J Psychol Res 2010;25(2):165-77.

10. Makame V, Ani C, GranthamMcgregor S. Psychological wellbeing of orphans in Dar El Salaam, Tanzania. Acta Paediatr 2002; 9l(4):459-65.

II. Halfon N, Zepeda A, Inkelas M. Mental health services for children in foster care. Los Angeles: UCLA Center for Healthier Children, Families and Communities 2002

12. Garvin MC, Tarullo AR, Van Ryzin M, Gunnar MR. Post adoption parenting and socioemotional development in post institutionalized children. Dev Psychopathol 2012; 24(0I):35-48.

13. Rahman W, Mullick MS, Pathan MA, Chowdhury NF, Shahidullah M, Ahmed $\mathrm{H}$, et al. Prevalence of behavioral and emotional disorders among the orphans and factors associated with these disorders. Bangabandhu Sheikh Mujib Med Uni J 20 I 2;5(I):29-34

14. Simsek Z, Erol N, Öztop D, Münir $K$. Prevalence and predictors of emotional and behavioral problems reported by teachers among institutionally reared children and adolescents in Turkish orphanages compared with community controls. Children Youth Ser Rev 2007;29(7):883-99.

15. Behavior Problems. Mental Health Treatment. [Cited on: April 02, 2017]. Available from URL: http://mentalhealthtreatment.net/b ehavior-problems

16. Santos LM, Queirós FC, Barreto ML, Santos DN. Prevalence of behavior problems and associated factors in preschool children from the city of Salvador, state of Bahia, Brazil. Rev Bras Psiquiatr 20I6;38(I):46-52. DOI: 10.1590/I5I6-4446-2014-I596

17. Elhamid AA, Howe A, Reading R. Prevalence of emotional and behavioral problems among 612 year-old children in Egypt. Soc Psychiatry Psychiatr Epidemiol $2009 ; 44$ ( I ):8 - I 4. DOI: I0.1007/s00 | 27-008-0394- |

18. Samarakkody D, Fernando D, Mcclure R, Perera H, De Silva H. Prevalence of externalizing behavior problems in Sri Lankan preschool children: birth, childhood, and sociodemographic risk factors. Soc Psychiatry Psychiatr Epidemiol 20। I;47(5):757-62. DOI: I0.1007/s00 I27-0 I I-0377-5

19. Ginige P, Tennakoon SU, Wijesinghe WH, Liyanage L, Herath PS, Bandara K. Prevalence of behavioral and emotional problems among seven to eleven-year-old children in selected schools in Kandy District, Sri Lanka. J Affect Disord 20। 4; I67:I67-70. DOI: 10.1016/j.jad.2014.05.062

20. Mullick MS, Goodman R. The prevalence of psychiatric disorders among 510 year olds in rural, urban and slum areas in Bangladesh: an 
exploratory study. Soc Psychiatry Psychiatr Epidemiol 2005;40(8): 663-7I. DOI: 10.1007/s00I27-0050939-5

2I. Srinath S, Girimaji SC, Gururaj G, Seshadri S, Subbakrishna DK, Bhola $P$, et al. Epidemiological study of child and adolescent psychiatric disorders in urban and rural areas of Bangalore, India. Indian J Med Res 2005; I 22(I):67-79.

22. Javed MA, Kundi MZ, Khan PA. Emotional and behavioral problems among school children in Pakistan. Pak Med Assoc 1992;42(8): I8I-3.

23. Syed EU, Hussein SA, Mahmud S. Screening for emotional and behavioral problems amongst $5 \mathrm{II}$ year-old school children in Karachi,
Pakistan. Soc Psychiatry Psychiatr Epidemiol 2007;42(5):42 I-7.

24. Bandeali S, Jawad A, Azmatullah A, Liaqaut HB, Aqeel I, Afzal A, et al. Prevalence of behavioral and psychological problems in working children. J Pak Med Assoc 2008;58 (6):345-9.

25. Goodman R, Ford T, Simmons $H$, Gatward R, Meltzer H. Using the Strengths and Difficulties Questionnaire (SDQ) to screen for child psychiatric disorders in a community sample. Br J Psychiatry 2000; 177(6):534-9.

26. Lassi ZS, Mahmud S, Syed EU, Janjua NZ. Behavioral problems among children living in orphanage facilities of Karachi, Pakistan: Comparison of children in an SOS Village with those in conventional orphanages. Soc Psychiatry Psychiatr Epidemiol 20। 0;46(8):787-96. DOI: 10.1007/s00 I27-010-0248-5

27. Eapen V, Jakka ME, Abou-Saleh MT. Children with psychiatric disorders: The Al Ain community psychiatry survey. Can J Psychiatry 2003;48(6):402-7. DOI: I0.1 I77/070674370304800607

28. Freud A, Solint A, Goldstein H. Beyond the best interest of the child, London: Andre Deutsch; 1973.

29. Bowlby J. Maternal care and mental health. Geneva: World Health Organization; 1951 Mar.

\section{AUTHOR'S CONTRIBUTION}

Following authors have made substantial contributions to the manuscript as under:

FK: Concept, acquisition of data, drafting the manuscript, final approval of the version to be published

NM: Study design, critical revision, drafting the manuscript, final approval of the version to be published

ZK: Analysis \& interpretation of data, critical review, final approval of the version to be published

Authors agree to be accountable for all aspects of the work in ensuring that questions related to the accuracy or integrity of any part of the work are appropriately investigated and resolved.

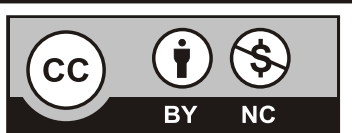

This is an Open Access article distributed under the terms of the Creative Commons Attribution-NonCommercial 2.0 Generic License.
KMUJ web address: www.kmuj.kmu.edu.pk

Email address: kmuj@kmu.edu.pk 